\title{
Article \\ Refined Nomogram Incorporating Standing Cough Test Improves Prediction of Adjustable Trans-Obturator Male System (ATOMS) Success to Treat Post-Prostatectomy Male Stress Incontinence
}

\author{
Juan F. Dorado ${ }^{1}$ and Javier C. Angulo ${ }^{2,3, *}$ \\ 1 PeRTICA Statistical Solutions, Av. Leonardo Da Vinci, 8, OF217, Getafe, 28906 Madrid, Spain; \\ jfdorado@pertica.es \\ 2 Clinical Department, Faculty of Biomedical Science, Universidad Europea de Madrid, Carretera de Toledo, \\ Km 12.500, Getafe, 28905 Madrid, Spain \\ 3 Urology Service, Hospital Universitario de Getafe, Carretera de Toledo, Km 12.500, Getafe, \\ 28905 Madrid, Spain \\ * Correspondence: javier.angulo@universidadeuroepa.es; Tel.: +34-699497569
}

Citation: Dorado, J.F.; Angulo, J.C. Refined Nomogram Incorporating Standing Cough Test Improves

Prediction of Adjustable Trans-Obturator Male System (ATOMS) Success to Treat Post-Prostatectomy Male Stress Incontinence. J. Pers. Med. 2022, 12, 94. https://doi.org/10.3390/jpm 12010094

Academic Editors: José I. López and Claudia Manini

Received: 22 December 2021

Accepted: 9 January 2022

Published: 12 January 2022

Publisher's Note: MDPI stays neutral with regard to jurisdictional claims in published maps and institutional affiliations.

Copyright: (C) 2022 by the authors. Licensee MDPI, Basel, Switzerland. This article is an open access article distributed under the terms and conditions of the Creative Commons Attribution (CC BY) license (https:// creativecommons.org/licenses/by/ $4.0 /)$.

\begin{abstract}
Background: The adjustable transobturator male system (ATOMS) device serves to treat post-prostatectomy incontinence, as it enhances residual urinary sphincteric function by dorsal compression of the bulbar urethra. We investigated the clinical parameters affecting continence recovery using this device and developed a decision aid to predict success. (2) Methods: We reviewed consecutive men treated with first-time ATOMS for post-prostatectomy incontinence from 2014 to 2021 at our institution. Patient demographics, reported pads per day (PPD), 24-h pad-test and Standing Cough Test (SCT), results' grades 1-4, according to Male Stress Incontinence Grading Scale (MSIGS), and the International Consultation on Incontinence Questionnaire-Short Form (ICIQSF) questionnaire were assessed. Treatment success was defined as no pads or a single PPD with $\leq 20$-mL 24-h pad-test. Logistic regression was performed using a stepwise model (entry 0.15 and stay criterium 0.1) to evaluate independent variables' determinant of dryness. Receiver-operating characteristic (ROC) curves for predictive variables were evaluated and their area under curve (AUC) was compared. A nomogram was generated and internally validated to predict probability of treatment success. (3) Results: Overall, 149 men (median age 70 years, IQR 7) were evaluated with a median follow-up of 45 months (IQR 26). Twelve patients (8\%) had previous devices for incontinence, and 21 (14.1\%) had pelvic radiation. Thirty-five men $(23.5 \%)$ did not achieve continence after ATOMS adjustment (use of no or one security PPD with $\leq 20$-mL 24-h pad-test). In univariate analysis, Charlson comorbidity index $(p=0.0412)$, previous urethroplasty $(p=0.0187)$, baseline $\operatorname{PPD}(p<0.0001), 24-\mathrm{h}$ pad-test $(p<0.0001)$, MSIGS $(p<0.0001)$, and ICIQ-SF questionnaire score $(p<0.0001)$ predicted ATOMS failure. In a multivariable model, 24 -h pad-test $(p=0.0031)$, MSIGS $(p=0.0244)$, and radiotherapy $(p=0.0216)$ were independent variables, with AUC 0.8221 . The association of MSIGS and 24-h pad-test was the superior combination (AUC 0.8236). A nomogram to predict the probability of ATOMS failure using the independent variables identified was proposed. (4) Conclusions: Several variables were identified as predictive of success for ATOMS using clinical history, physical examination (MSIGS), and factors that evaluate urine loss severity (PPD, 24-h padtest, and ICIQ-SF questionnaire). MSIGS adds prognostic value to 24-h pad-test in assessing success of ATOMS device to treat post-prostatectomy incontinence. A nomogram was proposed to calculate the risk of ATOMS failure, which could be of interest to personalize the decision to use this device or not in the individual patient.
\end{abstract}

Keywords: male stress urinary incontinence; adjustable transobturator male system; predictive nomogram 


\section{Introduction}

Male stress urinary incontinence (SUI) after prostate cancer treatment is a very disturbing complication of this highly prevalent disease that accounts for approximately $15 \%$ of all cancers worldwide [1]. Since 2012, the adjustable trans-obturator male system (ATOMS) is increasingly used for the surgical treatment of moderate to severe male SUI $[2,3]$.

Compared to the artificial urinary sphincter (AUS), ATOMS does not need patient manipulation, a certain advantage as cognitive and functional considerations, such as manual dexterity, affect the natural history of AUS, especially in the older population [4]. Other advantages of ATOMS over AUS include lower risk of urethral atrophy, urethral erosion, and device infection, and, also, the possibility of postoperative adjustment [5-7]. The mode of action of ATOMS is based on the ventral compression of the bulbar urethra, exerted by a silicone cushion that can be filled both intraoperatively and postoperatively [8]. Additionally, although several studies confirm that ATOMS is less effective in radiated patients, it can be safely used in the radiated population $[9,10]$, which is not advisable in other fixed male slings [11].

The only randomized, controlled trial comparing fixed male sling versus AUS revealed the incontinence rate remains high after surgery, but also that both devices are useful to improve symptoms and quality of life [12]. Additionally, the DOMINO multicentric database has shown that the functional results of AUS and adjustable slings are comparable with proper preoperative patient assessment and selection [13].

Different factors can be assumed to contribute to treatment outcomes for the selection of the most proper procedure for individual patients [14]. However, studies are often limited by sample size and the use of different techniques, which may not be so comparable $[5,14]$. In this study, we intended to evaluate clinical factors readily available in routine practice to predict results of an individual technique, so that a personalized decision to use or not to use the device can be taken after analyzing the probability of achieving an optimal therapeutic result.

\section{Materials and Methods}

\subsection{Study Population}

We reviewed a prospectively maintained, Institutional Review Board-approved database of all men who underwent primary placement of ATOMS ${ }^{\circledR}$ (Agency for Medical Innovations, A.M.I.; Feldkirch, Austria) for SUI by the same surgical team in a university hospital, between March 2014 and July 2021. Inclusion criteria were bothering SUI after radical prostatectomy, persistent after pelvic floor exercises, in patients not considered candidates for an AUS implant because of some degree of residual sphincteric activity, and at least 3 months of follow-up after ATOMS surgery. In all cases, SUI was demonstrated by the Standing Cough Test (SCT).

Prior anti-incontinence procedures, prior urethroplasty, and pelvic irradiation were not exclusion criteria. The study was conducted in accordance with the Helsinki Declaration, and all subjects provided informed consent to participate in the study.

\subsection{Variables Investigated}

Clinical parameters registered were obtained from a standardized baseline visit before surgery. Preoperative, operative, and postoperative variables were investigated. Preoperative features included demographics (age, body mass index, ASA score, Charlson index), cancer characteristics and treatments ( $\mathrm{D}^{\prime}$ Amico risk group, radiotherapy, time since prostatectomy), and previous treatments for incontinence or urethral stricture. Continence severity baseline was assessed by SCT according to Male Stress Incontinence Grading Scale (MSIGS), 24-h pad-count (PPD), 24-h pad-test (mL), and International Consultation on Incontinence Questionnaire-Short Form (ICIQ-SF) questionnaire.

Pad-count and pad-test were registered as the average value of 3 consecutive days. The SCG ensured that patients had not voided for at least $1 \mathrm{~h}$ and completed a series of four forceful coughs in a standing position. Leakage was confirmed at examination with SCT in 
all patients. The pad was held bellow the urethral meatus and every patient was graded by the examiner according to the standardized MSIGS measurement of urine loss: 1. Only delayed drops; 2. Early drops without stream; 3. Initial drops followed by delayed stream; and 4. Early and persistent stream. The self-assessed ICIQ-SF provides a brief and robust measure to assess frequency (ICIQ item-3, 0-5 score), severity of leakage (ICIQ item-4, 0-6 score), and overall impact of incontinence (ICIQ item-5, 0-10 score). ICIQ-SF score is provided by the sum of these items (0-21 score). Urodynamic data were not included in this study, although urodynamic evaluation was generally performed to rule out obstruction and predominant detrusor overactivity.

Operative variables investigated included operative time, operative and postoperative complications (Clavien-Dindo classification), early postoperative pain (Visual Analogue Scale, 0-10) and postoperative de novo overactive bladder symptoms, need and cause of surgical revision, system filling after complete adjustment, and number of fillings. Evaluation of continence outcomes included 24-h pad-count (PPD) and 24-h pad-test (mL) after adjustment.

\subsection{Surgical Technique}

The ATOMS consists of a tape-shaped, mesh implant with a central integrated cushion and an access port. The surgical technique followed the original description of Seweryn et al. [2]. Under spinal anesthesia, the patient is placed in the lithotomy position, with a 14-Fr Foley catheter inserted. A vertical midline perineal incision is performed to expose bulbospongiosus muscle. The mesh arms are introduced through the obturator foramen using helical tunnelers in an outside-in technique by means of a rotary movement. The implant is brought into position by pulling the sling arms, so that the cushion gently compresses the urethra ventrally and the mesh arms are secured to the central cushion under tension. Lavage with $500 \mathrm{~mL}$ of a $240 \mathrm{mg}$ gentamicin solution is performed.

Perioperative filling is performed after venting the cushion, up to a regular atmospheric pressure (usually $8 \mathrm{~mL}$ filling) or a bit more. The port is placed subcutaneously in the scrotum at a readily accessible location in case postoperative adjustment is needed by serial additional filling through scrotal puncture, until continence is reached or maximum total filling of the system, $25 \mathrm{~mL}$ according to the manufacturer. Patients are periodically evaluated, in concert with their follow-up for prostate cancer.

\subsection{Study Endpoints}

The primary endpoint was the evaluation of effectiveness of ATOMS, defined as use of no or one safety pad/day with a 24 -h pad-test $\leq 20 \mathrm{~mL} /$ day. The median differential pad-test, comparing urine loss after ATOMS adjustment with respects to baseline, evaluates the magnitude of effect achieved with ATOMS implantation.

Predictive variables were investigated among clinical variables registered at baseline preoperative visit, including demographics, previous medical history, prostate cancer history, PPD, 24-h pad-test, MSGIS, and ICIQ-SF questionnaire. Based on the predictive variables identified, and their relative value for prediction, we aimed to propose a nomogram to calculate the probability of achieving continence with ATOMS. This tool could be of interest to counsel the individual patient upon the probability of incontinence cure with this implant.

\subsection{Statistical Analysis}

Statistics were calculated as the median values, interquartile range (IQR), and minimum and maximum for continuous variables, and as the frequency and percent for categorical data. Differences were calculated by the Wilcoxon rank sum test for continuous variables and the Fisher exact test for categorical ones. A $p$ value $<0.05$ was considered significant. The correlation between MSGIS and 24-h pad-test was evaluated. Logistic regression was performed using a stepwise model (entry 0.15 and stay criterium 0.1 ) to 
evaluate preoperatively defined independent variables' determinant of dryness (no pad or one safety pad/day with a 24-h pad-test $\leq 20 \mathrm{~mL}$ /day).

The association of predicted probabilities and observed responses was evaluated and area under receiver-operating characteristic (ROC) curve for the selected model and different combinations of predictive factors was calculated. The apparent and expected optimism-corrected performances of the model were calculated using the c-index of the model with internal (bootstrap iterations, 400 ) validation. Finally, a nomogram to predict the probability of ATOMS failure using the independent variables identified was proposed. The statistical analysis was developed using Statistical Analysis System 9.4 (SAS Institute Inc., Cary, NY, USA).

\section{Results}

\subsection{Description of Variables Investigated}

One hundred forty-one consecutive patients with ATOMS implant to treat SUI after prostate cancer treatment in a single institution were included in the study. Device used was always that with the silicone-covered, pre-attached scrotal port design. Table 1 summarizes clinical data.

All patients in this series were previously treated for local or locally advanced prostate cancer. Radical prostatectomy was performed a median of 48 months (IQR 41 months) before ATOMS implant. Additionally, 21 patients (14.1\%) had pelvic radiation. According to D'Amico risk classification, prostate cancer treated was high risk in 101 patients $(67.8 \%)$. Twelve patients $(8 \%)$ had previous devices for incontinence, but none had been formerly implanted with ATOMS before inclusion in the study. Preoperative urodynamic study included filling cystometry and pressure flow study was performed in 86 patients $(57.7 \%)$.

Table 1. Preoperative, operative, and postoperative data of patients included $(n=141)$.

\begin{tabular}{|c|c|}
\hline Variable & $n(\%)$ \\
\hline \multicolumn{2}{|l|}{ Preoperative data } \\
\hline Age, years, median (IQR, range) & $70(7,49-83)$ \\
\hline Body mass index, median (IQR, range) & $26.6(4.8,16.2-40.2)$ \\
\hline \multicolumn{2}{|l|}{ ASA score, $n(\%)$} \\
\hline ASA I category & $27(18.1)$ \\
\hline ASA II category & $97(65.1)$ \\
\hline ASA III category & $25(16.8)$ \\
\hline Charlson comorbidity index, median (IQR, range) & $4(2,1-9)$ \\
\hline Previous incontinence surgery, $n(\%)$ & $12(8 \%)$ \\
\hline Previous urethroplasty, $n(\%)$ & $11(7.4)$ \\
\hline Previous radiation, $n(\%)$ & $21(14.9)$ \\
\hline \multicolumn{2}{|l|}{$\mathrm{D}^{\prime}$ Amico prostate cancer risk group ${ }^{(1)}, n(\%)$} \\
\hline Low risk & $16(10.7)$ \\
\hline Intermediate risk & $32(21.5)$ \\
\hline High risk & $101(67.8)$ \\
\hline Time since prostatectomy, months, median (IQR, range) & $48(41,11-160)$ \\
\hline \multicolumn{2}{|l|}{ Male Stress Incontinence Grading Scale (MSIGS) ${ }^{(2)}, n(\%)$} \\
\hline MSIGS 1 (2) & $6(4)$ \\
\hline MSIGS $2(2)$ & $17(11.4)$ \\
\hline MSIGS $3^{(2)}$ & $73(49)$ \\
\hline MSIGS $4^{(2)}$ & $53(35.6)$ \\
\hline 24-h pad count (PPD) ${ }^{(3)}, n$, median (IQR, range) & $5(3,1-11)$ \\
\hline 24-h pad test, mL, median (IQR, range) & $500(460,100-1800)$ \\
\hline ICIQ-SF total, median (IQR, range) & $15(5,9-21)$ \\
\hline ICIQ-SF Question 1 & $4(0,3-5)$ \\
\hline ICIQ-SF Question 2 & $4(2,2-6)$ \\
\hline ICIQ-SF Question 3 & $6(3,3-10)$ \\
\hline
\end{tabular}


Table 1. Cont.

\begin{tabular}{|c|c|}
\hline Variable & $n(\%)$ \\
\hline \multicolumn{2}{|l|}{ Operative data } \\
\hline Operative time, min, median (IQR, range) & $55(22,25-135)$ \\
\hline Perioperative complication, $n(\%)$ & $2(1.4)$ \\
\hline Postoperative complications ${ }^{(4)}$, any grade, $n(\%)$ & $31(22)$ \\
\hline Grade I ${ }^{(4)}, n(\%)$ & $23(16.3)$ \\
\hline Grade II ${ }^{(4)}, n(\%)$ & $2(1.4)$ \\
\hline Grade III $^{(4)}, n(\%)$ & $6(4.3)$ \\
\hline VAS for pain (0-10), median (IQR, range) ${ }^{(5)}$ & $0(1,0-8)$ \\
\hline \multicolumn{2}{|l|}{ Postoperative data } \\
\hline Total filling volume, mL, median (IQR, range) & $15(8,8-37)$ \\
\hline Number of fillings, $n$, median (IQR, range) & $1(3,0-7)$ \\
\hline Follow-up since implant, months, median (IQR, range) & $45(26,6-89)$ \\
\hline Patients with pad-test $\leq 20 \mathrm{~mL}, n(\%)$ & $114(76.5)$ \\
\hline Patients with pad-test zero $\mathrm{mL}, n(\%)$ & $93(66)$ \\
\hline 24-h pad count (PPD), $n$, median (IQR, range) & $0(1,0-6)$ \\
\hline 24-h pad test, $\mathrm{mL}$, median (IQR, range) & $0(15,0-680)$ \\
\hline Differential 24 -h pad test ${ }^{(6)}, \mathrm{mL}$, median (IQR, range) & $500(460,30-1600)$ \\
\hline
\end{tabular}

(1) Before prostate cancer therapy; ${ }^{(2)}$ MSIGS according to standing cough test; ${ }^{(3)}$ PPD, pads-per-day; ${ }^{(4)}$ According to Clavien-Dindo classification; ${ }^{(5)}$ At discharge, usually on day 1 after surgery; ${ }^{(6)}$ Baseline minus after adjustment for 24-h pad-test, expressed in mL (magnitude change). ASA, American Society of Anesthesiologists; ICIQ-SF, International Consultation on Incontinence Questionnaire-Short Form.

\subsection{Evaluation of Continence Outcomes}

In 93 patients $(66 \%)$, the $24-\mathrm{h}$ pad-test after adjustment was $0 \mathrm{~mL}$. Defining continence use of 1 security PPD with $\leq 20$-mL 24-h pad-test, success to treat SUI occurred in 114 patients (76.5\%), while, conversely, 35 (23.5\%) did not achieve continence as defined. After ATOMS implant and postoperative adjustment, a 24-h pad test was reduced to a median $0 \mathrm{~mL}$ (IQR 15), which gives a statistically significant reduction compared to baseline $(p<0.0001)$, which corresponded to a median differential pad-test effect of $500 \mathrm{~mL}$ (460 IQR) (Figure 1).

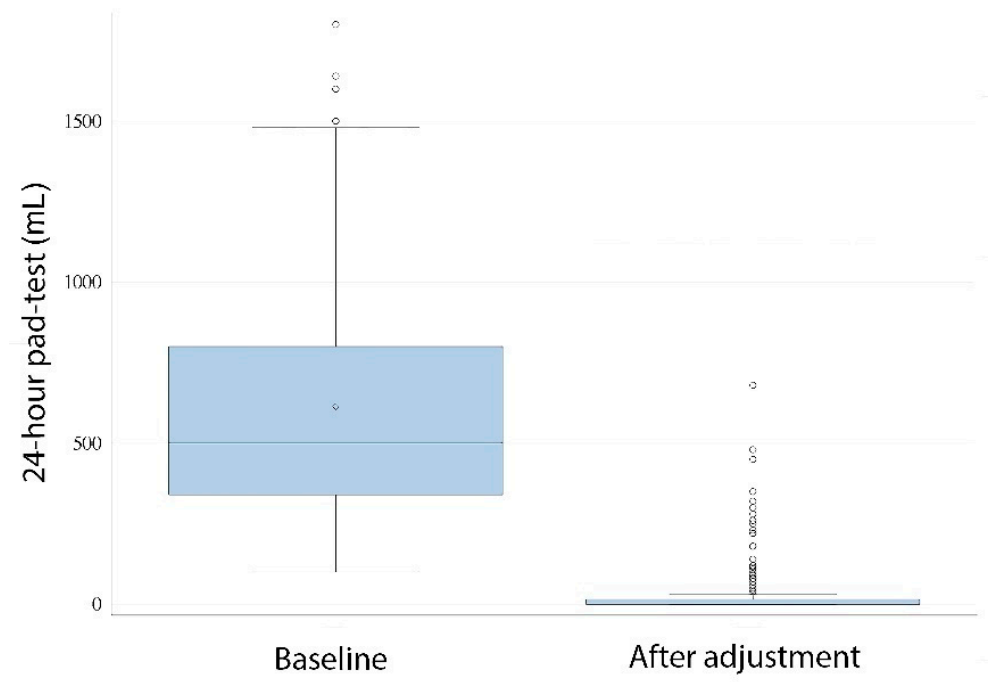

Figure 1. The 24-h, pad-test baseline compared to after adjustment $(t$-test, $p<0.0001)$.

\subsection{Preoperative Predictors of ATOMS Success}

Table 2 shows demographic and preoperative characteristics of patients undergoing ATOMS placement in the series investigated, stratified by treatment success. 
Table 2. Variables stratified by treatment success.

\begin{tabular}{cccc}
\hline Parameter & Success & \multirow{2}{*}{$\boldsymbol{p}$ Value } \\
\cline { 2 - 3 } & Yes $(\boldsymbol{n = 1 1 4 )}$ & No $(\boldsymbol{n = 3 5 )}$ & \\
\hline Patient age at implantation & $70(66-73)$ & $71(66-73)$ & 0.826 \\
BMI at implantation & $26.3(24-28.3)$ & $27.1(24.8-29.7)$ & 0.0876 \\
Charlson comorbidity index & $4(3-5)$ & $5(4-6)$ & 0.0376 \\
Previous urethroplasty & $5(4.4 \%)$ & $6(17.1 \%)$ & 0.021 \\
Previous incontinence device & $12(10.5)$ & $0(0 \%)$ & 0.0694 \\
Radiotherapy & $9(7.9 \%)$ & $12(34.3 \%)$ & 0.0003 \\
Intermediate-risk group & $29(25.4 \%)$ & $3(8.6 \%)$ & 0.0713 \\
Time since prostatectomy & $48(36-77)$ & $52(32-81)$ & 0.8332 \\
Pads per day & $4(3-6)$ & $8(6-8)$ & $<0.0001$ \\
24-h pad-test & $425(300-670)$ & $950(600-1200)$ & $<0.0001$ \\
MSIGS 4 & $27(23.7 \%)$ & $26(74.3 \%)$ & $<0.0001$ \\
ICIQ-SF & $14(13-18)$ & $18(14-21)$ & $<0.0001$
\end{tabular}

Continuous variables are presented as medians with interquartile ranges in parenthesis. MSIGS, Male Stress Incontinence Grading Scale; ICIQ-SF, International Consultation on Incontinence Questionnaire-Short Form.

Table 3 presents the corresponding odds ratios and confidence interval limits for each preoperative variable predictive of failure with ATOMS implant in the univariate analysis: Charlson comorbidity index, radiation, prostate cancer risk-group, previous urethroplasty, MSGIS group, PPD, 24-h pad-test, and ICIQ-SF total value. The multivariate analysis revealed MSIGS (category 4 vs. category 1; OR 3.412 (95\% C.I. 1.159-10.095); $p=0.0244$ ), radiotherapy for prostate cancer treatment (yes vs. no; OR 4.186 (95\% C.I. 1.225-14.472); $p=0.0216$ ), and $24-\mathrm{h}$ pad-test (>1300 mL vs. $\leq 900 \mathrm{~mL}$; OR 21.288 (95\% C.I. 2.93-443.628), and $900-1300 \mathrm{~mL}$ vs. $\leq 900 \mathrm{~mL}$; OR 5.591 (95\% C.I. 1.802-17.903); $p=0.0171)$ stayed as independent predictive factors of failure with ATOMS implant (Figure 2).

The accuracy of the predictive model defined by the combination of the independent variables of ATOMS failure (radiation, MSIGS, and 24-h pad-test) was $82.21 \%$. The area under the curve for MSIGS and pad-test $(82.36 \%)$ was superior to that of pad-test alone $(77.43 \%)$, although the difference did not reach statistical significance (ROC contrast estimation, $p=0.06$ ) (Figure 3).

Table 3. Logistic regression model to predict ATOMS failure.

\begin{tabular}{cccc}
\hline Univariate Analysis & Odds Ratio & 95\% CI & $p$-Value \\
\hline Charlson comorbidity index (2 vs. 1) & 2.717 & $1.101-7.752$ & 0.0412 \\
Radiotherapy (Yes vs. No) & 6.087 & $2.317-16.605$ & 0.0003 \\
Prostate cancer risk (Intermediate vs. Low) & 2.817 & $1.154-8$ & 0.0339 \\
Previous incontinence surgery (Yes vs. No) & 0.001 & $1.515-$ & 0.9617 \\
Previous urethroplasty (Yes vs. No) & 4.504 & $1.274-16.666$ & 0.0187 \\
MSIGS group (4 vs. 1) & 9.309 & $4.02-23.341$ & $<0.0001$ \\
PPD (per unit) & 1.826 & $1.448-2.39$ & $<0.0001$ \\
24-h pad-test (>1300 vs. $\leq 900 \mathrm{~mL}$ ) & 63.385 & $10.474-999$ & $<0.0001$ \\
24-h pad-test (900-1300 vs. $\leq 900 \mathrm{~mL}$ ) & 11.092 & $4.178-31.056$ & $<0.0001$ \\
ICIQ-SF (per unit) & 1.369 & $1.196-1.588$ & $p$-Value \\
\hline Multivariate Analysis & Odds Ratio & $\mathbf{9 5 \%}$ CI & 0.0244 \\
MSIGS group (4 vs. 1) & 3.412 & $1.159-10.095$ & 0.0216 \\
Radiotherapy (Yes vs. No) & 4.186 & $1.225-14.472$ & 0.0171 \\
24-h pad-test (>1300 vs. $\leq 900 \mathrm{~mL}$ ) & 21.288 & $2.93-443.628$ & $1.802-17.903$ \\
24-h pad-test (900-1300 vs. $\leq 900 \mathrm{~mL}$ ) & 5.591 & \\
\hline
\end{tabular}




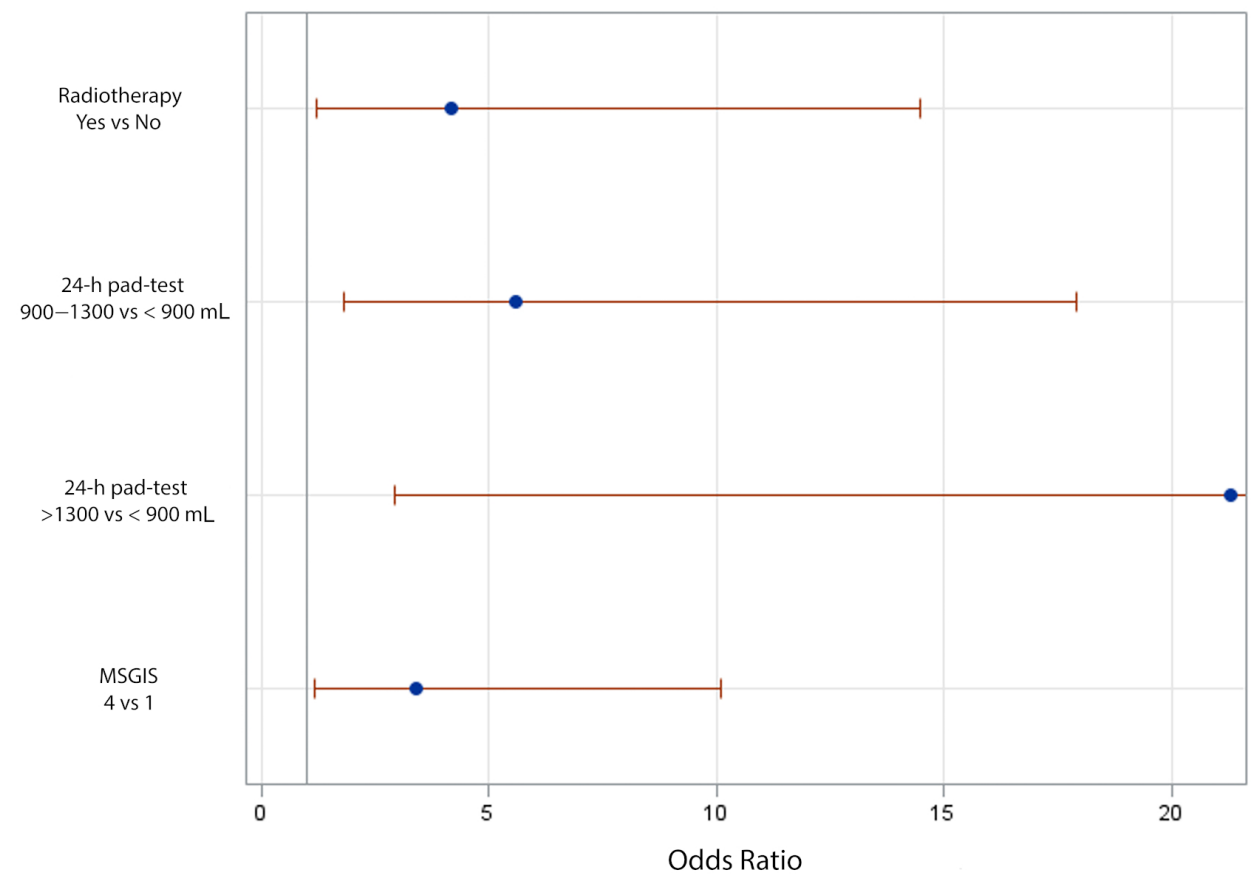

Figure 2. Odds ratios with $95 \%$ profile-likelihood confidence limits.

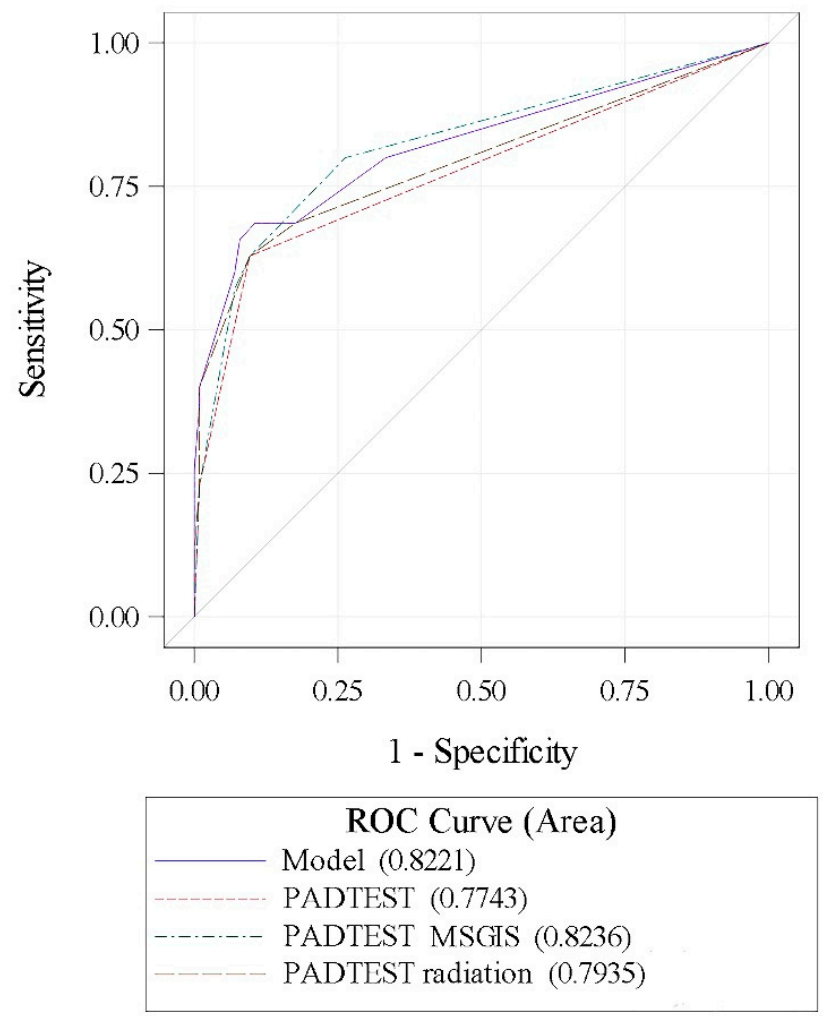

Figure 3. ROC curves for comparisons.

\subsection{Correlation between MSIGS and 24-h Pad-Test}

The Spearman's coefficient between MSIGS and pad-test was $\rho=0.76(p<0.0001)$, thus demonstrating a strong positive correlation (Figure 4). With each overall increase in MSIGS grading there was a relative increase on the average 24-h pad-test. Median (IQR) pad-test value was 180 (150) $\mathrm{mL}$ for patients with MSIGS = 1, 250 (70) $\mathrm{mL}$ for MSIGS = 2, 
420 (293) $\mathrm{mL}$ for MSIG = 3, and 900 (530) $\mathrm{mL}$ for MSIGS = 4 (Figure 4). This gives an idea on how MSIGS assessed by SCT is a rapid and reliable estimate of incontinence severity.

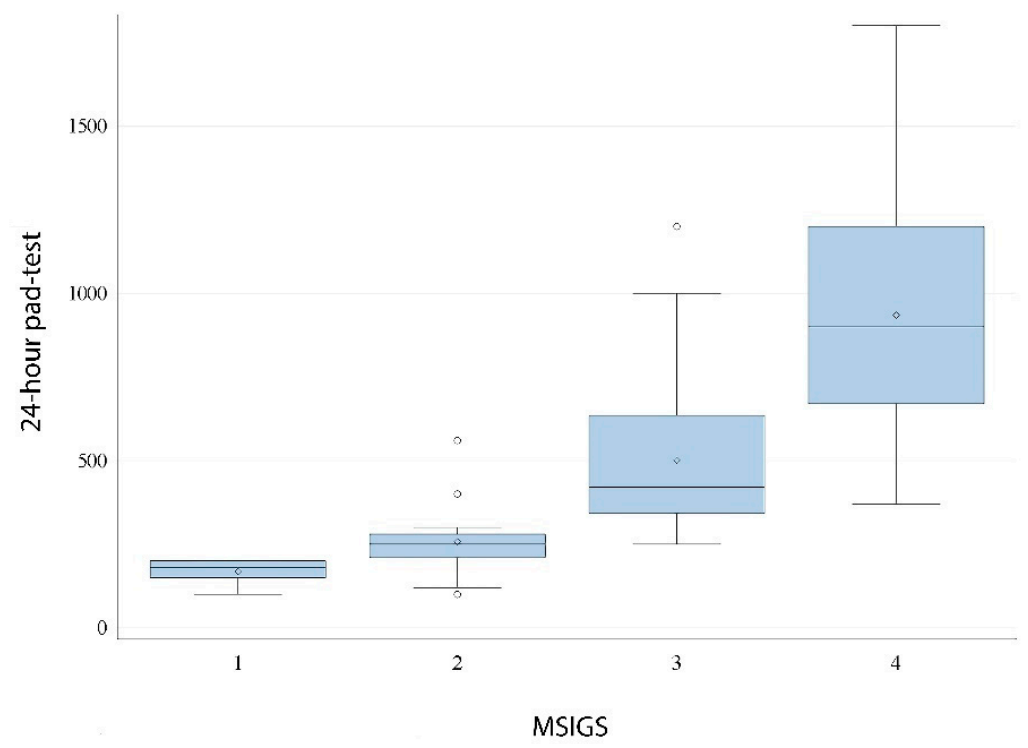

Figure 4. Distribution of 24-h pad-test by MSIGS (Spearman's $\rho=0.76 ; p<0.0001$ ).

\subsection{Nomogram Generation and Internal Validation}

Using the multivariate logistic regression model presented a nomogram can be generated to predict the overall probability of ATOMS failure in the particular patient (Figure 5). This model was internally validated by bootstrapping with 82.2\% (95\% CI 81.7-82.7) apparent performance and $11.1 \%$ (95\% CI 10.7-11.5) expected optimism.

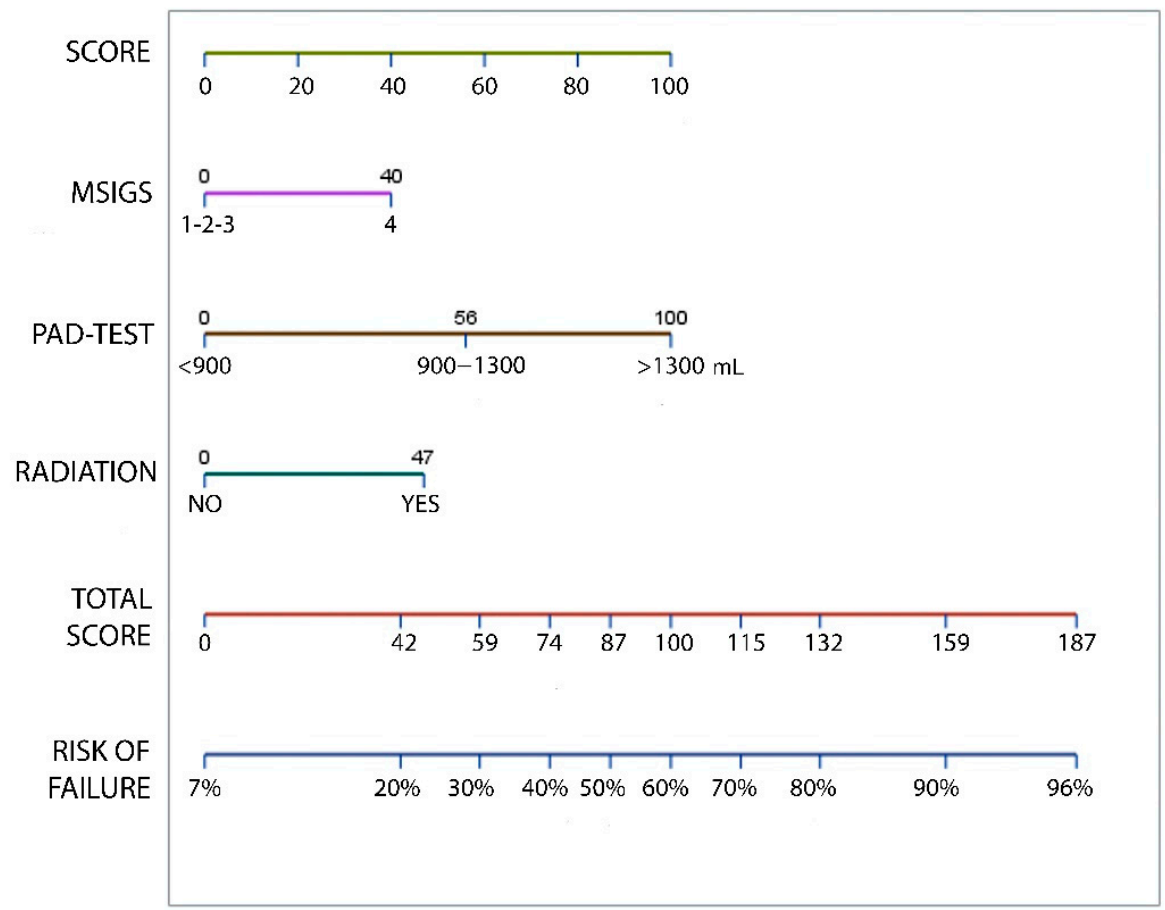

Figure 5. Nomogram predicting the probability of ATOMS failure, which can be calculated by obtaining the value for each parameter by drawing a straight line to the point axis, adding the points together, and finding the sum on the total point axis. 


\section{Discussion}

The selection of the ideal implant for the patient with moderate to severe male SUI is complicated even in centers of expertise. When offering both AUS and adjustable slings, the decision is mainly based on considering the history of radiation therapy and previous failed incontinence therapy [13]. Despite the scarcity of direct comparative studies, more complex patients are generally selected for an AUS implantation than for other options, and that may have a possible impact on the postoperative outcome $[5,13]$. Still though, the functional results and satisfaction with incontinence devices may be comparable $[5,12]$.

ATOMS is probably the adjustable sling with a larger accumulated body of evidence both regarding effectiveness and safety, especially compared to other adjustable continence systems for male SUI, such as Pro-ACT and Male Remeex System $[3,15,16]$. ATOMS is widely used in Europe and Canada as an alternative to AUS $[9,10,17,18]$ and is being currently evaluated by the FDA.

It can be a matter of debate whether adjustable slings, and specifically ATOMS, should only be used in patients with mild to moderate incontinence or if it can be used to treat selected patients with severe incontinence as well, taking into account that patients with total sphincteric deficiency are not good candidates for ATOMS and would be better treated with an AUS [8]. In this respect, patients with age-related cognitive decline are better treated with an ATOMS as no manipulation is needed for micturition with the adjustable device. Additionally, although the theoretical margin of SUI severity improvement (padtest change) for AUS exceeded that of ATOMS, the revision rate seems much higher for AUS $[5,6]$. Taking all this into account, it can be understandable that patient satisfaction after an ATOMS implant can be high, even when cases with severe SUI are included [19].

As was recently demonstrated, the SCT can help better stratify moderate male SUI (MSIGS 0-2 vs. 3-4) to more accurately predict sling success [20]. On the other hand, the 24-h pad-test provides a reliable and objective assessment of continence rates in patients with an AUS and strongly correlates to the ICIQ-SF score, so as to reduce reported outcome heterogeneity across studies [21]. However, some patients find it difficult and tedious to collect and weigh pads for a full $24-\mathrm{h}$ period, and also the variation of conditions from one day to another in water intake and exercise limits the applicability of the pad-test to make the decision whether to choose one or another technique. One can assume fixed slings can be used to treat the less severe cases, AUS the most severe ones, and adjustable slings have a better chance for those in between [22,23]. In this context, the SCT could have a role to better select candidates as it is a straightforward examination easily available in the clinic [24].

Many options have been suggested to ease the limitations of the 24-h pad-test. Use of a 1-h pad-test is an attractive option to facilitate the evaluation, but, despite the need for standardization of the test, it may not overcome the limitations of the 24-h evaluation [25]. On the other hand, a 7-day pad-test has been proposed as another alternative with added value in SUI after prostatectomy but is much more cumbersome for the patient [26]. Another strategy to evaluate incontinence severity is the self-administered ICIQ-SF questionnaire, a robust and also straightforward method to assess the impact of post-prostatectomy SUI [27], which can be used in conjunction with the pad count [28,29].

We confirmed that the modified SCT assessed by MSIGS is a rapid and reliable estimate of incontinence severity, as was originally demonstrated by Yi et al., based on the strong correlation between SCT, the 24-h pad-test, and the patient-reported PPD [30]. Additionally, for patients with detrusor overactivity and mixed incontinence, a pad-test may be less reliable than a cough (Valsalva-based) assessment [31]. Additionally, the incorporation of SCT to predictive models of sling success was confirmed to improve patient selection for fixed male transobturator sling [32].

Previous attempts to assess postoperative outcomes from the ATOMS and identify factors influencing failure to achieve continence agree that concurrent radiotherapy and increased pre-operative pad usage are independent factors associated with failure to achieve continence $[10,33]$. With the intention to improve patient selection for candidates to ad- 
justable transobturator male sling ATOMS, we developed a clinical tool to aid in preoperative patient evaluation and counseling. Urodynamics can help in the selection of optimal candidates for ATOMS by evaluation of preoperative voiding phase [34]. However, a more reproducible testing based on clinical preoperative variables is needed to improve the prediction of surgical failure. A nomogram based on a 24-h pad-test, SCT graded by MSIGS, and radiation previous history could be used to clinically support the decision of implanting ATOMS or AUS, especially in cases with moderate-severe urine loss. We did not include data of preoperative voiding phase by urodynamics in the multivariate analysis because they were not available in all the patients investigated.

The main limitation for this multivariate analysis and model development stands on the fact that it has been based on single-institution data, and external validation is advisable so that it can be generalized. Additionally, the definition of failure is rather stringent and does not consider patient-reported outcomes. The main strength of the model is that it is based on simple measurements. Patients without radiation, with a baseline 24-h padtest $\leq 900 \mathrm{~mL}$, and with SCT other than early and persistent stream are the best candidates to consider ATOMS implant. In fact, a pad-test median variation of $500 \pm 460 \mathrm{~mL}$ has been confirmed as a magnitude effect for ATOMS implant in this series, higher than the $200-400 \mathrm{~mL}$ that was observed after fixed male sling implant $[35,36]$.

\section{Conclusions}

In men with post-prostatectomy stress incontinence considered candidates for ATOMS implantation, quantification of the SCT seems a non-invasive and rapid assessment of incontinence severity, which correlates well with the 24-h pad-test. Outcomes of ATOMS regarding dryness after adjustment (use of no or one safety pad/day with a 24-h padtest $\leq 20 \mathrm{~mL} /$ day) can be predicted with a simple nomogram incorporating SCT (MSGIS scale), 24-h pad-test, and history of radiation. An ideal candidate for an ATOMS has baseline 24-h pad-test $\leq 900 \mathrm{~mL}$, SCT grades 1-3, and no history of radiation. This clinical tool was confirmed by bootstrap resampling but needs validation in an external cohort.

Author Contributions: Conceptualization, J.F.D. and J.C.A.; methodology, J.F.D. and J.C.A.; software, J.F.D.; validation, J.F.D.; formal analysis, J.F.D. and J.C.A.; investigation, J.F.D. and J.C.A.; resources, J.C.A.; data curation, J.C.A.; writing—original draft preparation, J.F.D. and J.C.A.; writingreview and editing, J.F.D. and J.C.A.; visualization, J.F.D. and J.C.A.; supervision, J.C.A.; project administration, J.C.A. All authors have read and agreed to the published version of the manuscript.

Funding: This research received no external funding.

Institutional Review Board Statement: The study was conducted according to the guidelines of the Declaration of Helsinki and approved by the Institutional Review Board (CEIm) Hospital Universitario de Getafe (protocol code A09/18, approved 2018).

Informed Consent Statement: Informed consent was obtained from all subjects involved in the study.

Data Availability Statement: Full data will be provided by the corresponding author upon reasonable request.

Conflicts of Interest: The authors declare no conflict of interest.

\section{References}

1. Bray, F.; Ferlay, J.; Soerjomataram, I.; Siegel, R.L.; Torre, L.A.; Jemal, A. Global cancer statistics 2018: GLOBOCAN estimates of incidence and mortality worldwide for 36 cancers in 185 countries. CA Cancer J. Clin. 2018, 68, 394-424. [CrossRef] [PubMed]

2. Seweryn, J.; Bauer, W.; Ponholzer, A.; Schramek, P. Initial experience and results with a new adjustable transobturator male system for the treatment of stress urinary incontinence. J. Urol. 2012, 187, 956-961. [CrossRef]

3. Esquinas, C.; Angulo, J.C. Effectiveness of Adjustable Transobturator Male System (ATOMS) to treat male stress incontinence: A systematic review and meta-analysis. Adv. Ther. 2019, 36, 426-441. [CrossRef] [PubMed]

4. Lavi, A.; Boone, T.B.; Cohen, M.; Gross, M. The patient beyond the sphincter-Cognitive and functional considerations affecting the natural history of artificial urinary sphincters. Urology 2020, 137, 14-18. [CrossRef] [PubMed] 
5. Esquinas, C.; Ruiz, S.; de Sancha, E.; Vazquez, M.; Dorado, J.F.; Virseda, M.; Arance, I.; Angulo, J.C. Outcomes of a series of patients with post-prostatectomy incontinence treated with an adjustable transobturator male system or artificial urinary sphincter. Adv. Ther. 2021, 38, 678-690. [CrossRef]

6. Angulo, J.C.; Schönburg, S.; Giammò, A.; Queissert, F.; Gonsior, A.; González-Enguita, C.; Martins, F.E.; Rourke, K.; Cruz, F. Artificial urinary sphincter or a second adjustable transobturator male system offer equivalent outcomes in patients whom required revision on the initial ATOMS device: An international multi-institutional experience. Neurourol. Urodyn. 2021, 40, 897-909. [CrossRef]

7. Angulo, J.C.; Rourke, K.; Queissert, F.; Giammò, A.; Schönburg, S.; Cruz, F.; Martins, F.E.; Gonsior, A.; González-Enguita, C. Adjustable transobturator male system (ATOMS) infection: Causative organisms and clinical profile. Urology 2021, 157, 120-127. [CrossRef]

8. Ruiz, S.; Virseda-Chamorro, M.; Queissert, F.; López, A.; Arance, I.; Angulo, J.C. The mode of action of adjustable transobturator male system (ATOMS): Intraoperative urethral pressure measurements. Uro 2021, 1, 45-53. [CrossRef]

9. Friedl, A.; Mühlstädt, S.; Zachoval, R.; Giammò, A.; Kivaranovic, D.; Rom, M.; Fornara, P.; Brössner, C. Long-term outcome of the adjustable transobturator male system (ATOMS): Results of a European multicentre study. BJU Int. 2017, 119, 785-792. [CrossRef]

10. Angulo, J.C.; Cruz, F.; Esquinas, C.; Arance, I.; Manso, M.; Rodríguez, A.; Pereira, J.; Ojea, A.; Carballo, M.; Rabassa, M.; et al. Treatment of male stress urinary incontinence with the adjustable transobturator male system: Outcomes of a multi-center Iberian study. Neurourol. Urodyn. 2018, 37, 1458-1466. [CrossRef] [PubMed]

11. Inouye, B.M.; Premo, H.A.; Weil, D.; Peterson, A.C. The male sling for stress urinary incontinence: Tips and tricks for success. Int. Braz. J. Urol. 2021, 47, 1131-1135. [CrossRef]

12. Abrams, P.; Constable, L.D.; Cooper, D.; MacLennan, G.; Drake, M.J.; Harding, C.; Mundy, A.; McCormack, K.; McDonald, A.; Norrie, J.; et al. Outcomes of a noninferiority randomised controlled trial of surgery for men with urodynamic stress incontinence after prostate surgery (MASTER). Eur. Urol. 2021, 79, 812-823. [CrossRef]

13. Grabbert, M.; Bauer, R.M.; Hüsch, T.; Kretschmer, A.; Kirschner-Hermanns, R.; Anding, R.; Brehmer, B.; Naumann, C.M.; Queissert, F.; Khoder, W.Y.; et al. Patient selection in surgical centers of expertise in the treatment of patients with moderate to severe male urinary stress incontinence. Urol. Int. 2020, 104, 902-907. [CrossRef] [PubMed]

14. Kim, M.; Choi, D.; Hong, J.H.; Kim, C.S.; Ahn, H.; Choo, M.S. Factors contributing to treatment outcomes of post-prostatectomy incontinence surgery for the selection of the proper surgical procedure for individual patients: A single-center experience. Neurourol. Urodyn. 2018, 37, 1978-1987. [CrossRef] [PubMed]

15. Angulo, J.C.; Schönburg, S.; Giammò, A.; Abellán, F.J.; Arance, I.; Lora, D. Systematic review and meta-analysis comparing Adjustable Transobturator Male System (ATOMS) and Adjustable Continence Therapy (ProACT) for male stress incontinence. PLoS ONE 2019, 14, e0225762. [CrossRef] [PubMed]

16. Angulo, J.C.; Ruiz, S.; Lozano, M.; Arance, I.; Virseda, M.; Lora, D. Systematic review and meta-analysis comparing Adjustable Transobturator Male System (ATOMS) and male Readjustment Mechanical External (REMEEX) system for post-prostatectomy incontinence. World J. Urol. 2020, 39, 1083-1092. [CrossRef]

17. Angulo, J.C.; Virseda-Chamorro, M.; Arance, I.; Ruiz, S.; Ojea, A.; Carballo, M.; Rodríguez, A.; Pereira, J.; Teyrouz, A.; Rebassa, M.; et al. Long-term outcome of adjustable transobturator male system for stress urinary incontinence in the Iberian multicentre study. Neurourol. Urodyn. 2020, 39, 1737-1745. [CrossRef]

18. Doiron, R.C.; Saavedra, A.; Haines, T.; Nadeau, G.; Tu, L.M.; Morisset, J.; Steele, S.; Valiquette, L.; Elterman, D.; Maciejewski, C.; et al. Canadian experience with the adjustable transobturator male system for post-prostatectomy incontinence: A multicenter study. J. Urol. 2019, 202, 1022-1028. [CrossRef]

19. Angulo, J.C.; Arance, I.; Ojea, A.; Carballo, M.; Rodríguez, A.; Pereira, J.; Rebassa, M.; Teyrouz, A.; Escribano, G.; Teba, F.; et al. Patient satisfaction with adjustable transobturator male system in the Iberian multicenter study. World J. Urol. 2019, 37, $2189-2197$. [CrossRef]

20. Khouri, R.K., Jr.; Yi, Y.A.; Ortiz, N.M.; Baumgarten, A.S.; Ward, E.E.; VanDyke, M.E.; Hudak, S.J.; Morey, A.F. Standing cough test stratification of moderate male stress urinary incontinence. Int. Braz. J. Urol. 2021, 47, 415-422. [CrossRef]

21. Reus, C.; Brattås, I.; Volz, D.; Sydén, F.; Grufman, K.H.; Mozer, P.; Renström-Koskela, L. Evaluation of the 24-h pad weight test as continence rate assessment tool after artificial urinary sphincter implantation for postprostatectomy urinary incontinence: A Swedish retrospective cohort study. Neurourol. Urodyn. 2021, 40, 1585-1592. [CrossRef]

22. Kretschmer, A.; Hübner, W.; Sandhu, J.S.; Bauer, R.M. Evaluation and management of postprostatectomy incontinence: A systematic review of current literature. Eur. Urol. Focus 2016, 2, 245-259. [CrossRef]

23. Redmond, E.J.; Nadeau, G.; Tu, L.-M.; Doiron, R.C.; Steele, S.S.; Herschorn, S.; Locke, J.A.; Maciejewski, C.C.; Dwyer, N.T.; Campeau, L.; et al. Author reply. Urology 2021, 148, 285-286. [CrossRef] [PubMed]

24. Angulo, J.C. Selecting the best candidate for a male incontinence device or another: Dream or nightmare? Int. Braz. J. Urol. 2021, 47, 423-425. [CrossRef]

25. Soto González, M.; Da Cuña Carrera, I.; Lantarón Caeiro, E.M.; Gutiérrez Nieto, M.; López García, S.; Ojea Calvo, A. Correlation between the 1-hour and 24-hour pad test in the assessment of male patients with post-prostatectomy urinary incontinence. Prog. Urol. 2018, 28, 536-541. [CrossRef] [PubMed] 
26. Martínez-Cuenca, E.; Sánchez, J.V.; Bonillo, M.A.; Morán, E.; Broseta, E.; Arlandis, S. Longer is better than shorter: The added value of the seven-day pad test in the post-radical prostatectomy urinary incontinence. Neurourol. Urodyn. 2021, 40, 994-1000. [CrossRef] [PubMed]

27. Avery, K.; Donovan, J.; Peters, T.J.; Shaw, C.; Gotoh, M.; Abrams, P. ICIQ: A brief and robust measure for evaluating the symptoms and impact of urinary incontinence. Neurourol. Urodyn. 2004, 23, 322-330. [CrossRef] [PubMed]

28. Tienza, A.; Graham, P.L.; Robles, J.E.; Diez-Caballero, F.; Rosell, D.; Pascual, J.I.; Patel, M.I.; Mungovan, S.F.; Cortes, G. Daily pad usage versus the International Consultation on Incontinence Questionnaire Short Form for continence assessment following radical prostatectomy. Int. Neurourol. J. 2020, 24, 156-162. [CrossRef]

29. García Cortés, A.; Colombás Vives, J.; Gutiérrez Castañé, C.; Chiva San Román, S.; Doménech López, P.; Ancizu Marckert, F.J.; Hevia Suárez, M.; Merino Narro, I.; Velis Campillo, J.M.; Guillén Grima, F.; et al. What is the impact of post-radical prostatectomy urinary incontinence on everyday quality of life? Linking Pad usage and International Consultation on Incontinence Questionnaire Short-Form (ICIQ-SF) for a COMBined definition (PICOMB definition). Neurourol. Urodyn. 2021, 40, 840-847. [CrossRef]

30. Yi, Y.A.; Keith, C.G.; Graziano, C.E.; Davenport, M.T.; Bergeson, R.L.; Christine, B.S.; Morey, A.F. Strong correlation between standing cough test and 24-hour pad weights in the evaluation of male stress urinary incontinence. Neurourol. Urodyn. 2020, 39, 319-323. [CrossRef]

31. Henderson, J.W.; Kane, S.M.; Mangel, J.M.; Kikano, E.G.; Garibay, J.A.; Pollard, R.R.; Mahajan, S.T.; Debanne, S.M.; Hijaz, A.K. A randomized comparative study evaluating various cough stress tests and 24-hour pad test with urodynamics in the diagnosis of stress urinary incontinence. J. Urol. 2018, 199, 1557-1564. [CrossRef]

32. Shakir, N.A.; Fuchs, J.S.; McKibben, M.J.; Viers, B.R.; Pagliara, T.J.; Scott, J.M.; Morey, A.F. Refined nomogram incorporating standing cough test improves prediction of male transobturator sling success. Neurourol. Urodyn. 2018, 37, 2632-2637. [CrossRef] [PubMed]

33. Redmond, E.J.; Nadeau, G.; Tu, L.M.; Doiron, R.C.; Steele, S.S.; Herschorn, S.; Locke, J.A.; Maciejewski, C.C.; Dwyer, N.T.; Campeau, L.; et al. Multicentered assessment of clinical outcomes and factors associated with failure of the Adjustable TransObturator Male System (ATOMS). Urology 2021, 148, 280-286. [CrossRef]

34. Virseda-Chamorro, M.; Ruiz, S.; García, G.; Queissert, F.; Salinas, J.; Arance, I.; Angulo, J.C. Do voiding urodynamic parameters predict the success of adjustable transobturator male system (ATOMS) to treat postprostatectomy urinary incontinence? Neurourol. Urodyn. 2020, 39, 1746-1752. [CrossRef]

35. Cornu, J.N.; Sèbe, P.; Ciofu, C.; Peyrat, L.; Cussenot, O.; Haab, F. Mid-term evaluation of the transobturator male sling for post-prostatectomy incontinence: Focus on prognostic factors. BJU Int. 2011, 108, 236-240. [CrossRef] [PubMed]

36. Collado Serra, A.; Resel Folkersma, L.; Domínguez-Escrig, J.L.; Gómez-Ferrer, A.; Rubio-Briones, J.; Solsona Narbón, E. AdVance/AdVance XP transobturator male slings: Preoperative degree of incontinence as predictor of surgical outcome. Urology 2013, 81, 1034-1039. [CrossRef] [PubMed] 